Chesters, C. G. C. \& Rolinson, G. N. (1951). J. gen. Microbiol. 5, 559-565.

\title{
Trace Elements and Streptomycin Production
}

\author{
By C. G. C. CHESTERS and G. N. ROLINSON* \\ Department of Botany, University of Nottingham
}

\begin{abstract}
SUMMARY: Using a defined medium capable of purification free from trace elements the relationship between the latter and streptomycin production by Streptomyces griseus was investigated. Zinc and copper were essential for antibiotic production in as much as they were essential for growth. In the case of iron, approximately five times as much was required for antibiotic production as for growth alone. It was not possible to demonstrate that manganese was essential for either growth or antibiotic production.
\end{abstract}

The experiments reported below were carried out to investigate the relationship between trace elements and antibiotic production by $S$. griseus and to find whether those trace elements already shown to be indispensable for the growth of higher plants, algae, fungi and bacteria are also required by this actinomycete. As far as we are aware, such trace elements have not been shown to be essential for any species in the Actinomycetales. Some of the present findings have already been reported briefly elsewhere (Chesters \& Rolinson, 1950).

Certain statements have been made concerning the growth and antibiotic production of $S$. griseus in relation to trace elements. Woodruff (1947) found that zinc favoured growth but inhibited streptomycin production, and conversely, iron depressed growth but enhanced streptomycin production; the optimum concentration of iron was found to be 30 p.p.m. and of zinc, 10 p.p.m. Spilsbury (1948) reported that the addition of 50 p.p.m. of iron had no significant effect on either growth or streptomycin production, and that 10 p.p.m. of zinc decreased both growth and production of streptomycin. Johnstone \& Waksman (1948), using $S$. bikiniensis found that, whereas iron had little effect on antibiotic production, 50 p.p.m. zinc sulphate had a considerable stimulating effect, and, when both ions were added, iron partly neutralized the favourable effect of zinc. Both iron and magnesium were reported by LePage \& Campbell (1946) to give a general increase in the yield of streptomycin. According to Reynolds $\&$ Waksman (1948) iron has a very favourable effect on the production of grisein by $S$. griseus. It is evident that trace elements influence the growth and antibiotic production of $S$. griseus but the precise relationships are confused.

\section{METHODS}

Care was taken throughout to ensure that the growth medium and glassware were rendered as free as possible from the trace elements under investigation, and that subsequent contamination by these elements was avoided. All water used was distilled twice in a Pyrex-glass still. The defined medium described by Lumb (1949) was used throughout the experiments. Traces of zinc and copper

\footnotetext{
* Present address: Boots Pure Drug Co. Ltd., Research Department, Bacteriological Division, Oakfields Road, West Bridgford, Nottingham.
} 
were removed by extraction with chloroform solutions of diphenylthiocarbazone (dithizone) at pH 7.3 (Feeney, Lightbody \& Garibaldi, 1947). Iron and manganese were removed in a similar manner, using 8-hydroxyquinoline (oxine) (Waring \& Werkman, 1943) at $\mathrm{pH} 5 \cdot 2$ for iron and $\mathrm{pH} \mathbf{7 \cdot 3}$ for manganese. In all experiments the concentration of one trace element was varied in turn while the remaining trace elements were kept at the following concentrations: iron, 5.0 p.p.m.; zinc, manganese and copper, 2.0 p.p.m.; and molybdenum, 1.0 p.p.m.

The strain of $S$. griseus used was supplied through the courtesy of Boots Pure Drug Co. and was a selected variant of the original Waksman 4 strain. To avoid carry-over of metals in the spores of the inoculum, felts were grown on $50 \mathrm{ml}$. of purified medium in $\mathbf{5 0 0} \mathrm{ml}$. Hysil or Pyrex flasks, and after aseptically removing the culture liquor, were shaken for $5 \mathrm{~min}$. with $50 \mathrm{ml}$. of sterile doubledistilled water. This suspension was filtered through sintered glass of porosity 3 before use and $\mathbf{1 . 0} \mathrm{ml}$. used to inoculate each flask.

The experiments were carried out with $20 \mathrm{ml}$. of medium in $100 \mathrm{ml}$. conical Hysil or Pyrex flasks sterilized at $15 \mathrm{lb}$./sq.in. for $15 \mathrm{~min}$. All cultures were incubated at $28^{\circ}$ for 8 days.

The assay of antibiotic activity was carried out by the cylinder-cup method using Bacillus subtilis N.C.T.C. 7241 as test organism. All figures given are the average of eight ring assays of three replicate cultures. Growth was estimated as total dry-weight mycelium per flask. All figures are the average of three replicate cultures.

\section{RESULTS}

The effect of zinc on growth and streptomycin production

Treatment of the culture medium with dithizone removes copper as well as zinc. Copper was therefore added as $\mathrm{CuSO}_{4} \cdot \mathbf{5 H}_{2} \mathrm{O}$ to the purified medium to give a concentration of 2 p.p.m. of copper, and graded amounts of zinc as $\mathrm{ZnSO}_{4} \cdot 7 \mathrm{H}_{2} \mathrm{O}$ added to a series of replicates.

Fig. 1 shows that zinc is indispensable for the growth of $S$. griseus. With no added zinc the purified culture solution supported little growth. When zinc

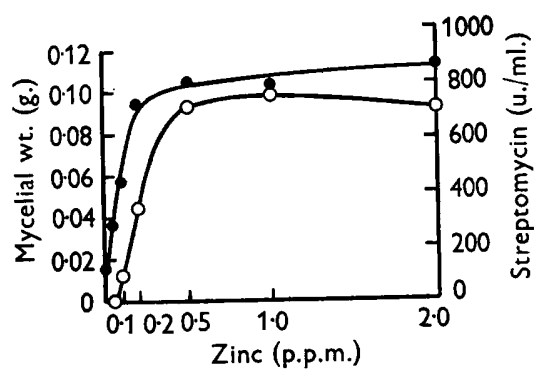

Fig. 1

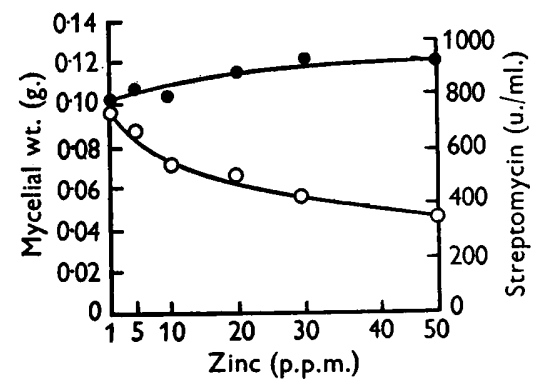

Fig. 2

Fig. 1. The effect of zine deficiency on growth (-C) and streptomycin production $(\mathrm{O}-\mathrm{O})$.

Fig. 2. The effect of high concentrations of zinc on growth production $(\mathrm{O}-\mathrm{O})$. 
was partially deficient (0.1-0.2 p.p.m.) the mycelial felt was thin, had little aerial mycelium and no spores. Lysis occurred in submerged areas of the felt. Maximum development of aerial mycelium and of spores was not obtained with less than 1.0 p.p.m. of zinc; larger amounts of zinc merely accelerated the rate of growth to a slight extent.

The optimum concentration of zinc for antibiotic production was 1.0 p.p.m. At concentrations above 1.0 p.p.m., zinc depressed antibiotic production and at 50 p.p.m. the titre was only half that at the optimum level. The results shown in Figs. 1 and 2 agree with those of Woodruff (1947) and Spilsbury (1948), who reported that concentrations of zinc above 10 p.p.m. depressed antibiotic production. Our results, however, indicate that the optimum concentration is relatively low and that quantities in excess of 1.0 p.p.m. are unfavourable for antibiotic production.

\section{The effect of iron on growth and streptomycin production}

The culture medium was purified with oxine and $2 \cdot 0$ p.p.m. of zinc, manganese and copper and 1.0 p.p.m. of molybdenum added to restore the concentrations of these metals. Iron, as $\mathrm{FeSO}_{4} \cdot 7 \mathrm{H}_{2} \mathrm{O}$, was added in graded amounts to a series of replicates.

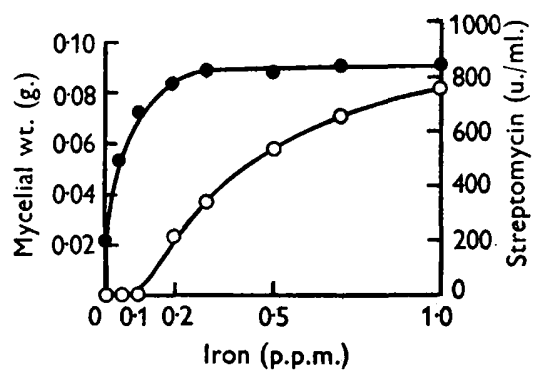

Fig. 3

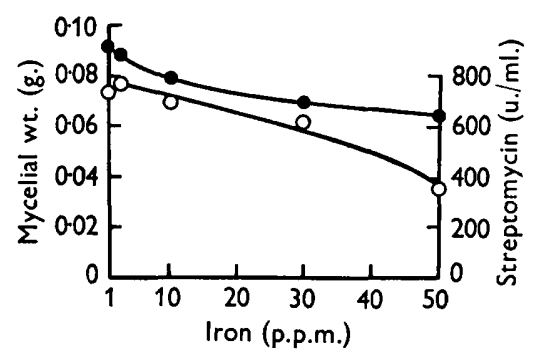

Fig. 4

Fig. 3. The effect of iron deficiency on growth (- $(\mathrm{O}-\mathrm{O})$.

Fig. 4. The effect of high concentrations of iron on growth (-) and streptomycin production $(\mathrm{O}-\mathrm{O})$.

Fig. 3 shows that iron is essential for the growth of $S$. griseus. Iron deficiency, unlike zinc deficiency, does not result in abnormal growth. Sporulation occurred even with the lowest concentration of iron and increased up to $0.5 \mathrm{p} . \mathrm{p} . \mathrm{m}$. The effect of higher concentrations of iron is shown in Fig. 4. Beyond 1.0 p.p.m. growth decreased steadily and the spores became pink, giving a pronounced tint to the whole felt which deepened to a rose pink at 50 p.p.m.

At low concentrations the effect of iron on antibiotic production did not run parallel with the effect on growth (Fig. 3). While with 0.1 p.p.m. of iron growth was $c .80 \%$ of maximum, antibiotic production had not reached a measurable value. At concentrations between $\mathbf{0 \cdot 2}$ and 1.0 p.p.m., iron showed a specific effect on antibiotic production. Over this range, growth was almost unaltered, whereas antibiotic production rose from a very low level to almost the maximum 
value. Whereas 0.3 p.p.m. was sufficient for optimum growth, optimum antibiotic production required between 1.0 and 2.0 p.p.m. of iron. With higher concentrations of iron, growth and antibiotic production were both appreciably reduced. With 50 p.p.m. of iron, growth was c. $75 \%$ of the maximum and streptomycin production only $45 \%$ of the maximum (Fig. 4).

\section{The effect of copper on growth and streptomycin production}

Copper was found to be a difficult element to remove from the culture solution and to guard against as a contaminant. The medium was extracted with dithizone, and sufficient $\mathrm{ZnSO}_{4} \cdot 7 \mathrm{H}_{2} \mathrm{O}$ added to restore the concentration of 2.0 p.p.m. of zinc. To decrease the carry-over of copper in the spores of the inoculum the latter was passaged on a purified medium and inoculation carried out by means of an all-glass spray. Using this method of inoculation $0 \cdot 1 \mathrm{ml}$. spore suspension per flask was sufficient, as compared with $1.0 \mathrm{ml}$. used when inoculated by a pipette.

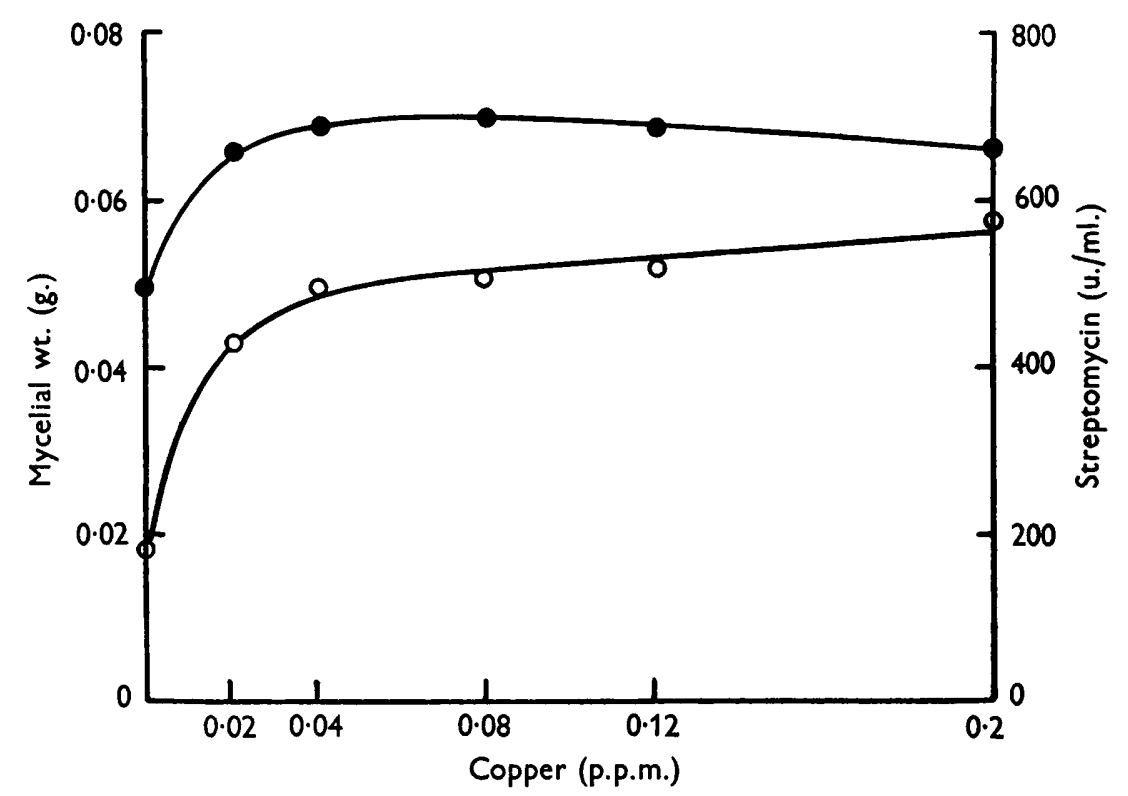

Fig. 5. The effect of copper deficiency on growth (- - ) and streptomycin production $(\mathrm{O}-\mathrm{O})$.

The effect of copper deficiency on growth and antibiotic production is shown in Fig. 5. Although the deficiency in growth produced in these experiments from a lack of copper was not so marked as with the lack of zinc or iron, it is clear from Fig. 5 that the metal is nevertheless essential. Cultures without added copper were only $\mathbf{7 2} \%$ of the weight of normal cultures. If a completely copper-free culture could be realized it is almost certain that no growth would occur. Copper deficiencies were indicated also by the colour of the spores, which changed from the normal dirty white through grey to dark brown-grey as the copper deficiency became more acute. 
Without added copper the titre was less than $30 \%$ of the maximum value (Fig. 5). The minimum amount of copper for optimum antibiotic production was approximately the same as for growth, i.e. $0 \cdot 05$ p.p.m., although titres did tend to increase slightly with increasing amounts of copper up to as much as 1.0 p.p.m. Above 1.0 p.p.m., concentrations of copper up to 50 p.p.m. showed little effect on either growth or antibiotic production. Compared with the results of Spilsbury (1948), our results indicate that the copper requirements of $S$. griseus are relatively small and that no marked inhibitory effects occur at concentrations of even 50 p.p.m. Providing 0.05 p.p.m. of copper was present this metal appeared to have little effect on $S$. griseus.

The effect of manganese on growth and streptomycin production

When the medium was purified by means of oxine and the trace elements other than manganese returned, the mycelial growth produced after spray inoculation showed neither deficiency of growth nor of antibiotic production in

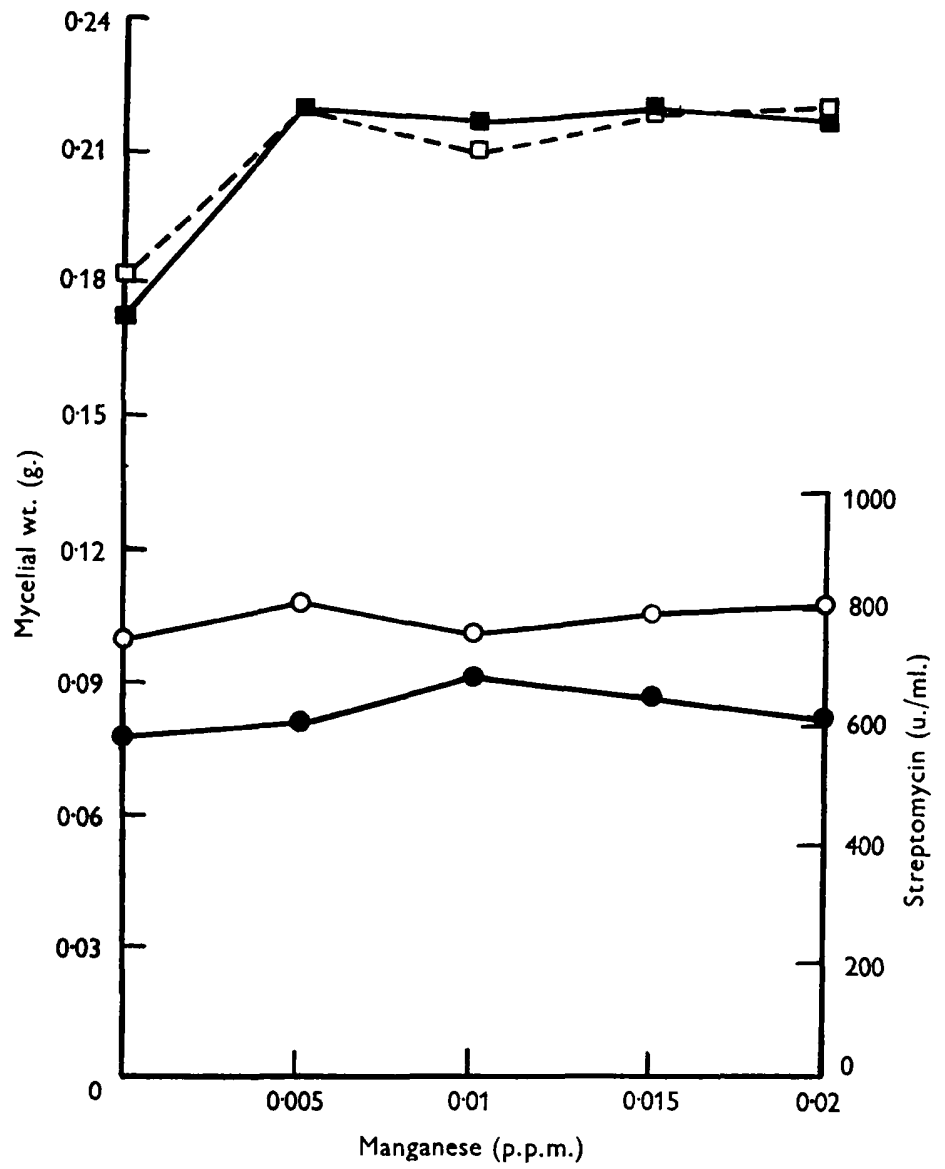

Fig. 6. The effect of manganese on the growth of $S$. griseus (-_- ) and on streptomycin production $(\mathrm{O}-\mathrm{O})$ and on the growth of $\boldsymbol{A}$. niger in the same medium and with sterilized $S$. griseus inoculum present in the medium ( $\square \cdots \cdots \square)$. 
any of the experiments. The spore suspensions used were prepared from felts which had been grown through three passages on such a purified medium. The purified medium was also tested by inoculation with Aspergillus niger which had been grown on a purified medium containing only 0.01 p.p.m. manganese. Marked manganese deficiencies were at once obtained with $A$. niger. With no added manganese the cultures were completely devoid of spores and consequently white, in contrast with the normal jet-black appearance, and the mycelial weights of these deficient cultures were decreased to $c .80 \%$ of normal. It was quite evident that the purified medium did not contain sufficient manganese for the normal growth of $A$. niger yet when inoculated with $S$. griseus neither growth nor streptomycin production were diminished. The growth of $A$. niger showed the same degree of deficiency when the $S$. griseus inoculum was added to the purified medium before sterilization. This experiment, together with the fact that the inoculum was passaged three times on the purified medium, suggested that the manganese content of the inoculum was not appreciable. Fig. 6 shows these effects of manganese on the growth of $A$. niger and $S$. griseus and also on streptomycin production. The absence of any decrease in streptomycin production when no manganese was added was more remarkable than the absence of growth deficiency, since with the other trace elements studied streptomycin production suffered more than growth as the metal became deficient.

Manganese has been shown to be required by a wide range of living organisms and it seems not unlikely that it is essential for life in general. If manganese is in fact essential for the growth of $S$. griseus the minimum amount required would appear to be extremely small and certainly less than 0.005 p.p.m. Concentrations of manganese up to 50 p.p.m. had little effect on growth or antibiotic production other than to depress the latter slightly.

\section{DISCUSSION}

With the exception of iron, none of the trace elements studied here showed any marked effect on antibiotic production other than by way of altered growth, and providing a sufficient concentration was present for growth, antibiotic production was also optimum. With regard to iron, however, normal growth was not itself sufficient to achieve optimum antibiotic production. Some mechanism would appear to exist in streptomycin formation which requires approximately five times the quantity of iron sufficient for growth alone.

The apparently conflicting reports which have been published on the effects of trace elements on streptomycin production may be largely due to the use of complex media which may contain considerable quantities of trace elements. Such media may well furnish sufficient trace elements for optimum growth without any intentional addition. Complex media containing natural products such as meat extract are more likely to contain toxic quantities of trace elements than to be deficient. Fig. 2 shows that this might very well occur in the case of zinc where quantities greater than 1.0 p.p.m. inhibited streptomycin production in the medium used. 
The fact that zinc, iron and copper are essential for the growth of $S$. griseus agrees with the findings for a wide range of green plants, fungi and bacteria, and lends support to the probability that these elements are indispensable to life in general. The apparently minute manganese requirement of $S$. griseus is remarkable, and it would be of interest to know whether this is characteristic of other actinomycetes.

The authors wish to express their gratitude to Boots Pure Drug Co. Ltd. for the award of a Fellowship to one of us (G.N.R.) to enable this work to be carried out.

\section{REFERENCES}

Chesters, C. G. C. \& Rolinson, G. N. (1950). Aspects of the trace element nutrition of Streptomyces griseus. J. gen. Microbiol. 4, 1.

Feeney, R. E., Lightbody, H. D. \& Garibaldi, J. A. (1947). Zinc as an essential element for growth and subtilin formation by Bacillus subtilis. Arch. Biochem. $15,13$.

Johnstone, D. B. \& Waksman, S. A. (1948). The production of streptomycin by Streptomyces bikiniensis. J. Bact. 55, 317.

LePage, G. A. \& Campbell, R. (1946). Preparation of streptomycin. J. biol. Chem. $162,163$.

Lumb, M. (1949). Biochemical investigations of fermentations of the Actinomycetales. Ph.D. Thesis, University of London.

Reynolds, D. M. \& Waksman, S. A. (1948). Grisein, an antibiotic produced by certain strains of Streptomyces griseus. J. Bact. 55, 739.

SPILSBURY, J. F. (1948). Observations on the nutritional requirements of Streptomyces griseus (Krainsky) Waksman \& Schatz. Trans. Brit. mycol. Soc. 31, 210.

WARING, W. A. \& WERKMaN, C. H. (1943). Growth of bacteria in an iron-free medium. Arch. Biochem. 1, 303.

WoodrufF, H. B. (1947). The production of streptomycin in stationary culture on liquid and solid substrate. J. Bact. 54, 42.

(Received 7 March 1951) 